\title{
Single-dose prednisolone alters endocrine and haematologic responses and exercise performance in men
}

\author{
Alexander Tacey ${ }^{1,2, *}$, Lewan Parker ${ }^{1,3, *}$, Bu B Yeap ${ }^{4}$, John Joseph ${ }^{5}$, Ee M Lim ${ }^{5}$, Andrew Garnham ${ }^{1}$, David L Hare ${ }^{6}$, \\ Tara Brennan-Speranza ${ }^{7}$ and Itamar Levinger ${ }^{1,2}$ \\ ${ }^{1}$ Institute for Health and Sport (IHES), Victoria University, Melbourne, Victoria, Australia \\ ${ }^{2}$ Department of Medicine-Western Health, Australian Institute for Musculoskeletal Science (AIMSS), Melbourne Medical School, The University of \\ Melbourne, Melbourne, Victoria, Australia \\ ${ }^{3}$ Institute for Physical Activity and Nutrition, Deakin University, Geelong, Victoria, Australia \\ ${ }^{4}$ Medical School, University of Western Australia, and Department of Endocrinology and Diabetes, Fiona Stanley Hospital, Perth, Western \\ Australia, Australia \\ ${ }^{5}$ PathWest Laboratory Medicine, Sir Charles Gairdner Hospital, Perth, Western Australia, Australia \\ ${ }^{6}$ University of Melbourne and the Department of Cardiology, Austin Health, Melbourne, Victoria, Australia \\ ${ }^{7}$ Department of Physiology and Bosch Institute for Medical Research, University of Sydney, Sydney, New South Wales, Australia \\ Correspondence should be addressed to I Levinger: itamar.levinger@vu.edu.au \\ *(A Tacey and L Parker contributed equally to this work)
}

\section{Abstract}

The aim of this study was to investigate the effect of a single dose of prednisolone on (A) high-intensity interval cycling performance and (B) post-exercise metabolic, hormonal and haematological responses. Nine young men participated in this double-blind, randomised, cross-over study. The participants completed exercise sessions $(4 \times 4$ min cycling bouts at $90-95 \%$ of peak heart rate), $12 \mathrm{~h}$ after ingesting prednisolone $(20 \mathrm{mg}$ ) or placebo. Work load was adjusted to maintain the same relative heart rate between the sessions. Exercise

\section{Key Words}

- high-intensity interval exercise

- glucocorticoids

- glucose metabolism

- sex hormones performance was measured as total work performed. Blood samples were taken at rest, immediately post exercise and up to $3 \mathrm{~h}$ post exercise. Prednisolone ingestion decreased total work performed by $5 \%(P<0.05)$. Baseline blood glucose was elevated following prednisolone compared to placebo $(P<0.001)$. Three hours post exercise, blood glucose in the prednisolone trial was reduced to a level equivalent to the baseline concentration in the placebo trial $(P>0.05)$. Prednisolone suppressed the increase in blood lactate immediately post exercise $(P<0.05)$. Total white blood cell count was elevated at all timepoints with prednisolone $(P<0.01)$. Androgens and sex hormone-binding globulin were elevated immediately after exercise, irrespective of prednisolone or placebo. In contrast, prednisolone significantly reduced the ratio of testosterone/luteinizing hormone $(P<0.01)$. Acute prednisolone treatment impairs high-intensity interval cycling performance and alters metabolic and haematological parameters in healthy young men. Exercise may be an effective tool to minimise the effect of prednisolone on blood glucose levels.

\section{Introduction}

Glucocorticoids (GC) are a naturally occurring catabolic steroid, produced by the hypothalamic-pituitaryadrenal (HPA) axis and regulated by neuroendocrine and immune responses $(1,2)$. Synthetic forms of GC, such as prednisolone, are used primarily for antiinflammatory purposes in the treatment of numerous https://ec.bioscientifica.com https://doi.org/10.1530/EC-18-0473 (c) 2019 The authors Published by Bioscientifica Ltd

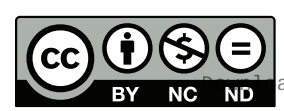

This work is licensed under a Creative Commons Attribution-NonCommercial-NoDerivatives 4.0 Internationab kicense.ifica.com at 04/26/2023 10:53:39AM 
acute and chronic illnesses and diseases $(3,4,5)$. As much as $17 \%$ of the population are prescribed GC on an annual basis, indicating the substantial prevalence of GC administration (6).

GC are often used by athletes for their proposed ergogenic effects, which has resulted in the World AntiDoping Agency banning their use during competition. Several recent reviews suggest that short-term ( $>2$ weeks) GC treatment likely has an ergogenic effect on exercise capacity and performance $(7,8)$. However, the effects of acute (single dose) GC administration are less clear, largely due to limited research. As such, it is important to determine the biological effects of acute GC treatment, not only for the potential effects on performance but also for the health implications associated with GC treatment.

GC administration at supraphysiological doses can result in severe systemic side effects. In severe cases of prolonged GC treatment, this can result in iatrogenic Cushing's syndrome with skin thinning and bruising, reduced bone density, accumulation of central adiposity, skeletal muscle wasting and hyperglycaemia (9). The withdrawal of exogenous GC or minimisation of dose and duration of therapy are recommended to minimise GC-induced side effects (10). However, this is not always possible and as such additional pharmaceutical drugs are often prescribed to treat GC-related symptoms, which may lead to the development of further unwanted side effects (10). Emerging research from animal studies has demonstrated the potential for exercise to be a viable alternative for managing certain GC-induced side effects, including skeletal muscle atrophy and insulin resistance $(11,12,13)$. Yet, there is little evidence in humans regarding the potential benefits of exercise to treat and manage the cardiometabolic side effects of GC treatment.

In men, chronic or long-term GC treatment is associated with a reduction in circulating testosterone concentrations attributed to the inhibition of the hypothalamic-pituitary-testicular (HPT) axis (14). Exercise is not thought to interfere with the diurnal rhythm of testosterone production (15), and there may be a short-term effect of exercise training to reduce metabolic clearance of testosterone (16). However, how acute administration of GC may modulate sex hormone responses to exercise in men is unclear.

Therefore, the primary aims of this study were (A) to determine whether a single dose of prednisolone can influence exercise performance during high-intensity interval cycling and (B) to investigate the effects of acute prednisolone administration on metabolic, haematological and hormonal outcomes and determine the response to high-intensity exercise.

\section{Methods}

This study is part of a larger study and as such a detailed description of the methodology is provided elsewhere (17, 18). In short, nine healthy, recreationally active males (age: $27.8 \pm 1.7$ years; BMI: $24.4 \pm 0.8$; fasting blood glucose: $4.7 \pm 0.2 \mathrm{mmol} / \mathrm{L}$, Mean \pm s.E.M.) participated in this doubleblind, randomised controlled, cross-over study. The participants orally ingested either prednisolone $(20 \mathrm{mg})$ or placebo (Avicel), $12 \mathrm{~h}$ prior to undergoing an acute exercise session. The second session (either prednisolone or placebo) was completed after a washout period of at least 1 week. The high-intensity interval exercise (HIIE) consisted of $4 \times 4$ min cycling bouts at $90-95 \%$ of peak heart rate, interspersed with 2-min recovery periods at 50-60\% of peak heart rate. We, and others, have previously reported that this type of exercise elicits favourable improvements in glycaemic control, compared to moderate-intensity exercise $(19,20)$. The workload for the second session was continuously modified throughout the exercise to elicit the same heart rate achieved during the first session. Informed consent was obtained from each participant and the study was approved by the Victoria University Human Research Ethics Committee.

Blood samples were taken prior to exercise, immediately after exercise, and $30 \mathrm{~min}, 1 \mathrm{~h}, 2 \mathrm{~h}$ and $3 \mathrm{~h}$ post exercise. Blood glucose and lactate concentrations were analysed using YSI 2300 STAT Plus (Glucose \& Lactate Analyser, Australia). White blood cell (WBC) counts, red blood cell (RBC) counts, haemoglobin and haematocrit concentrations were analysed with a Sysmex KX $-21 \mathrm{~N}$ (Kobe, Japan). Serum testosterone and dihydrotestosterone (DHT) were measured by liquid chromatography massspectrometry using a Xevo TQ-S (Waters Corporation, Milford, MA, USA) with prior liquid-liquid extraction using methyl tert-butyl ether. The lowest limit of detection of testosterone and DHT is $0.08 \mathrm{nmol} / \mathrm{L}$. Serum oestradiol (E2) was analysed by liquid chromatography mass spectrophotometry following derivatisation with Dansyl Chloride. The lowest limit of detection is $5 \mathrm{pmol} / \mathrm{L}$. The between-run imprecision for LCMS analysis of testosterone, DHT and E2 over the analytical range is $5-10 \%$. Serum sex hormone-binding globulin (SHBG) was analysed on an Immulite 2000 (Siemens Healthcare Diagnostics Inc.) and luteinizing hormone (LH) on an Architect Analyser (Abbott Diagnostics).

This work is licensed under a Creative Commons Attribution-NonCommercial-NoDerivatives 4.0 Internationab ticense.ifica com at $04 / 26 / 2023$ 10:53:39AM 


\section{Statistical analysis}

Data were checked for normality and analysed using Predictive Analytics Software (PASW, SPSS Inc.). Comparison of means was examined using a twoway (Treatment $\times$ Time) repeated-measures ANOVA. For all significant interaction and main effects, a priori comparisons of means (baseline vs all post-exercise timepoints; placebo vs glucocorticoid for all time-points) were conducted using Fisher's least significant difference test $(P<0.05)$. All data are reported as mean \pm standard error of mean (S.E.M.) and all statistical analysis were conducted at the $95 \%$ level of significance $(P \leq 0.05)$. Trends were reported when $P$ values were greater than 0.05 and less than 0.1. Effect sizes (ESs) were calculated using Cohen's d equation.

\section{Results}

\section{Exercise performance}

Prednisolone did not significantly affect the work performed in the first bout of HIIE. In contrast, prednisolone significantly decreased the work performed in the final three HIIE bouts, the difference became greater with each subsequent set (ES: 0.22-0.41, Fig. 1). Overall, the total work performed during the exercise session was significantly lower with prednisolone compared to placebo (prednisolone: $206 \mathrm{kj}$; placebo: $217 \mathrm{kj}, P<0.05$ ). As expected, HR was not significantly different between each set, with and without prednisolone, as each set was matched according to HR (all P>0.05, ES: 0.03-0.14). However, the mean difference for the entire session was slightly higher (1.5bpm, $P<0.05$, ES: 0.1) following prednisolone (Fig. 1).

\section{Blood glucose}

Prednisolone ingestion caused a significant increase in blood glucose concentration at baseline, immediately following exercise and $30 \mathrm{~min}, 1$ and $2 \mathrm{~h}$ after exercise, compared to placebo (ES: 0.55-2.19, Fig. 2A). Blood glucose concentration in the placebo trial was not significantly altered from baseline throughout the session. Three hours following exercise, blood glucose levels in the prednisolone session were equivalent to the glucose concentration in the placebo session $(P>0.05)$.

\section{Blood lactate}

The acute administration of prednisolone did not alter baseline blood lactate concentrations. The HIIE caused an

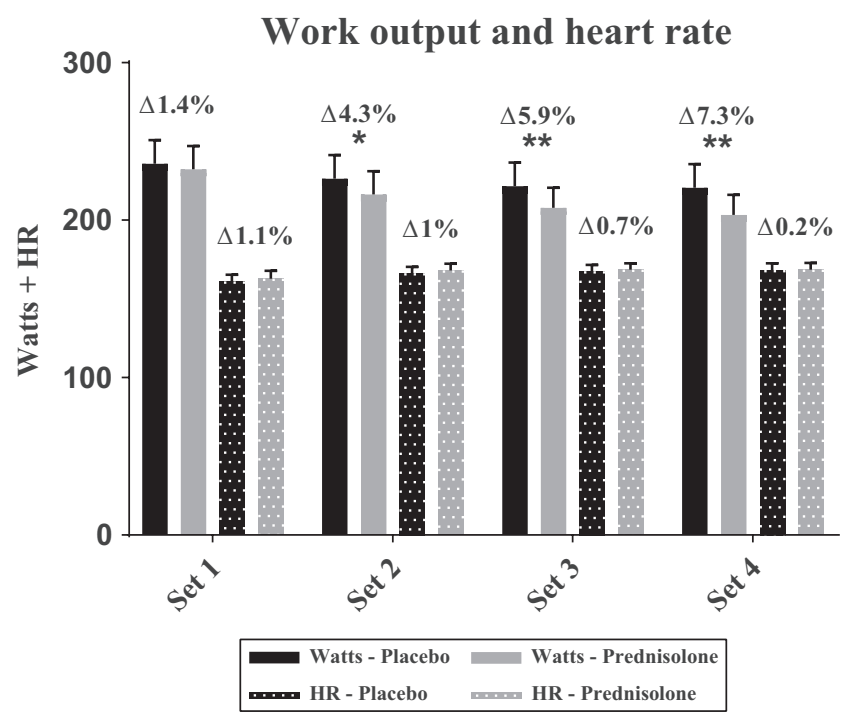

Figure 1

Mean work output (Watts) (solid bars) and heart rate (HR) (striped bars) during the high-intensity cycling sets. $\Delta$ expressed as a percentage difference between treatments. ${ }^{*} P<0.01,{ }^{*} P<0.05$ prednisolone significantly different from placebo.

increase blood lactate concentration with both treatments; however, the increase in lactate was reduced by $14 \%$ with prednisolone compared to the placebo $(P<0.05$, ES: 0.55$)$ (Fig. 2B). Blood lactate returned to baseline levels after $1 \mathrm{~h}$ of recovery in the prednisolone session, but remained elevated above baseline for up to $3 \mathrm{~h}$ post-exercise in the placebo session (Fig. 2B).

\section{Haematology}

Due to machine technical difficulties which resulted in missing data, results for haematological variables are reported for seven participants only.

In comparison to baseline, whole blood WBC concentration was significantly increased immediately following exercise, 2 and $3 \mathrm{~h}$ after exercise, for both treatments (Fig. 3A). Compared to placebo, prednisolone caused a significant elevation in whole blood WBC counts at all time-points $(P<0.01$, ES: 1.18-2.01).

The HIIE caused a significant increase in whole blood RBC, haemoglobin and haematocrit immediately post exercise for both treatments $(P<0.05$, ES: 1.2-2.23) (Fig. 3B, C and D). With both treatments combined whole blood RBC count decreased below baseline levels at $1 \mathrm{~h}$ post exercise $(P<0.05)$. Similarly, haemoglobin and haematocrit concentrations were decreased below baseline levels for up to $1 \mathrm{~h}$ after exercise $(P<0.05)$, returning to baseline levels 2 and $3 \mathrm{~h}$ into recovery. Prednisolone had no significant effect on whole blood




A Glucose \& Lactate

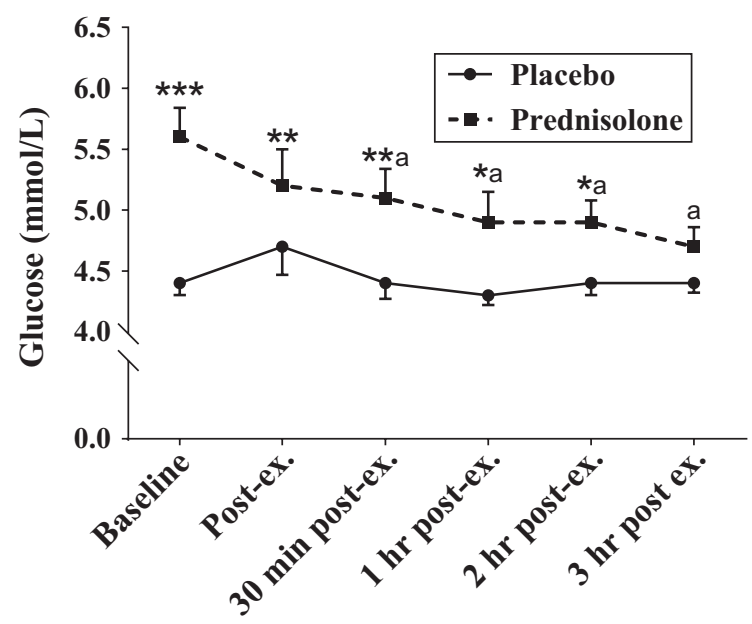

B

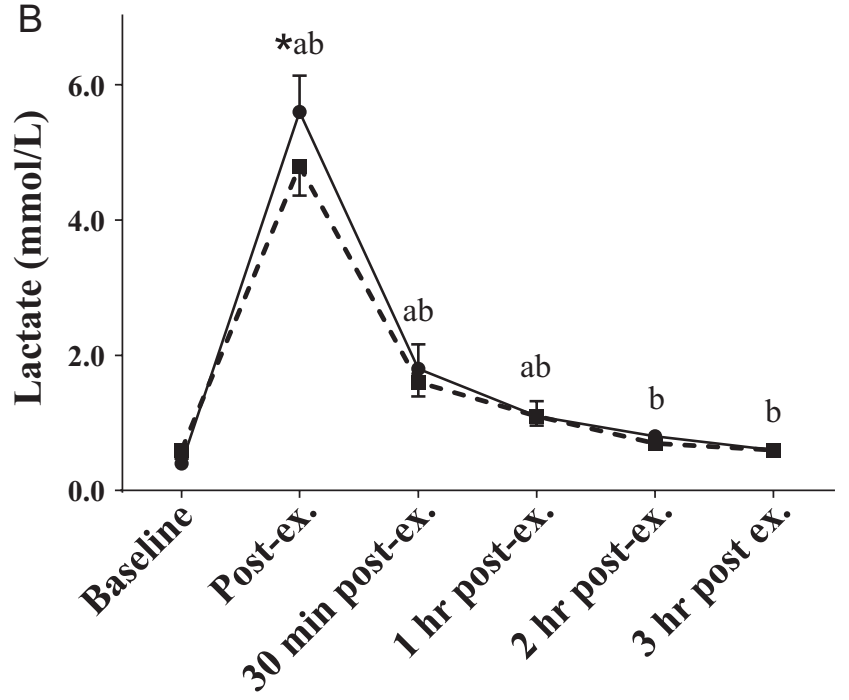

Figure 2

(A) Blood glucose, (B) blood lactate responses (means \pm S.E.M.) $12 \mathrm{~h}$ post capsule ingestion (baseline), immediately post exercise (Post-ex) and throughout recovery: $30 \mathrm{~min}, 1 \mathrm{~h}, 2 \mathrm{~h}$ and $3 \mathrm{~h}$ with prednisolone and placebo treatment. ${ }^{*} P<0.05, * * P<0.01, * * * P<0.001$ between prednisolone and placebo treatment. (a) Different from baseline values with prednisolone ingestion $(P<0.05)$. (b) Different from baseline values with placebo treatment $(P<0.05)$.

RBC count, haemoglobin or haematocrit compared to placebo $(P<0.05$, ES: $0-0.32)$.

\section{Sex hormones}

Serum concentrations of testosterone, DHT and SHBG increased immediately after exercise with both placebo and prednisolone treatments combined (Fig. 4A, B and E, $P<0.05)$. DHT and SHBG concentrations decreased below baseline levels $1 \mathrm{~h}$ following exercise, before returning to pre-exercise levels $3 \mathrm{~h}$ post exercise (Fig. $4 \mathrm{~B}$ and E).
Similarly, testosterone decreased below baseline levels $1 \mathrm{~h}$ into recovery and remained reduced at $3 \mathrm{~h}$ post exercise (Fig. 4A). E2 was significantly elevated above baseline concentrations $3 \mathrm{~h}$ after exercise, irrespective of treatment (Fig. 4C, ES: 0.46-0.82).

A trend was observed for higher LH at all time-points with prednisolone; however, the effect was not significant $(P=0.087$, ES: 0.17-1.24) (Fig. 4D). A significant treatment effect was observed in the ratio of testosterone/LH, with prednisolone causing a reduction in the ratio of testosterone/LH at all time-points in comparison to placebo (Fig. 5A, $P<0.01$, ES: 0.56-1.3). Prednisolone did not significantly alter the testosterone/E2 ratio (Fig. 5B).

\section{Discussion}

The major findings of this study are (A) a single dose of prednisolone decreases work capacity during HIIE at $\sim 95 \%$ of peak HR in healthy young men; (B) prednisolone significantly elevates fasting blood glucose concentrations which is restored to baseline $3 \mathrm{~h}$ after HIIE; (C) exercise acutely affects WBC counts and sex hormones which persists up to $3 \mathrm{~h}$ after exercise, while prednisolone reduces the ratio of testosterone/LH.

There is a lack of evidence regarding the effect of acute (single dose) GC treatment during HIIE, despite shortterm GC treatment indicating an ergogenic effect $(7,8)$. We report a significant reduction in the work completed, at the same relative intensity during HIIE, with prior prednisolone ingestion. This finding corresponds with a previous study which reported that acute prednisolone ingestion (20 mg) increased $\mathrm{VO}_{2}$ during steady state cycling at $60 \%$ of $\mathrm{VO}_{2 \max }$, indicating an increased energy demand during submaximal exercise, which may indicate reduced exercise efficiency (21). In contrast, HIIE following an acute $4 \mathrm{mg}$ dose of dexamethasone appears to have no effect on $\mathrm{VO}_{2}$ or HR (22). Similarly, single-dose prednisolone $(20 \mathrm{mg}$ ) has no effect on time to exhaustion at intensities between 70 and $85 \%$ of $\mathrm{VO}_{2 \max }$ $(23,24)$. Together, the current evidence indicates that acute prednisolone reduces exercise capacity, especially at higher intensities, when the metabolic demand is high. The mechanisms by which GC reduces exercise capacity are not clear, but may be related to the acute effect of GC on skeletal muscle protein signalling including aberrant anabolic and insulin signalling proteins (18), and/or impaired skeletal muscle microvascular blood flow (25), both known mediators of exercise capacity. The discrepancy between our findings and others that have (c) 2019 The authors Published by Bioscientifica Ltd
This work is licensed under a Creative Commons Attribution-NonCommercial-NoDerivatives 4.0 enternationad ticense ifica.com at 04/26/2023 10:53:39AM 
Haematology
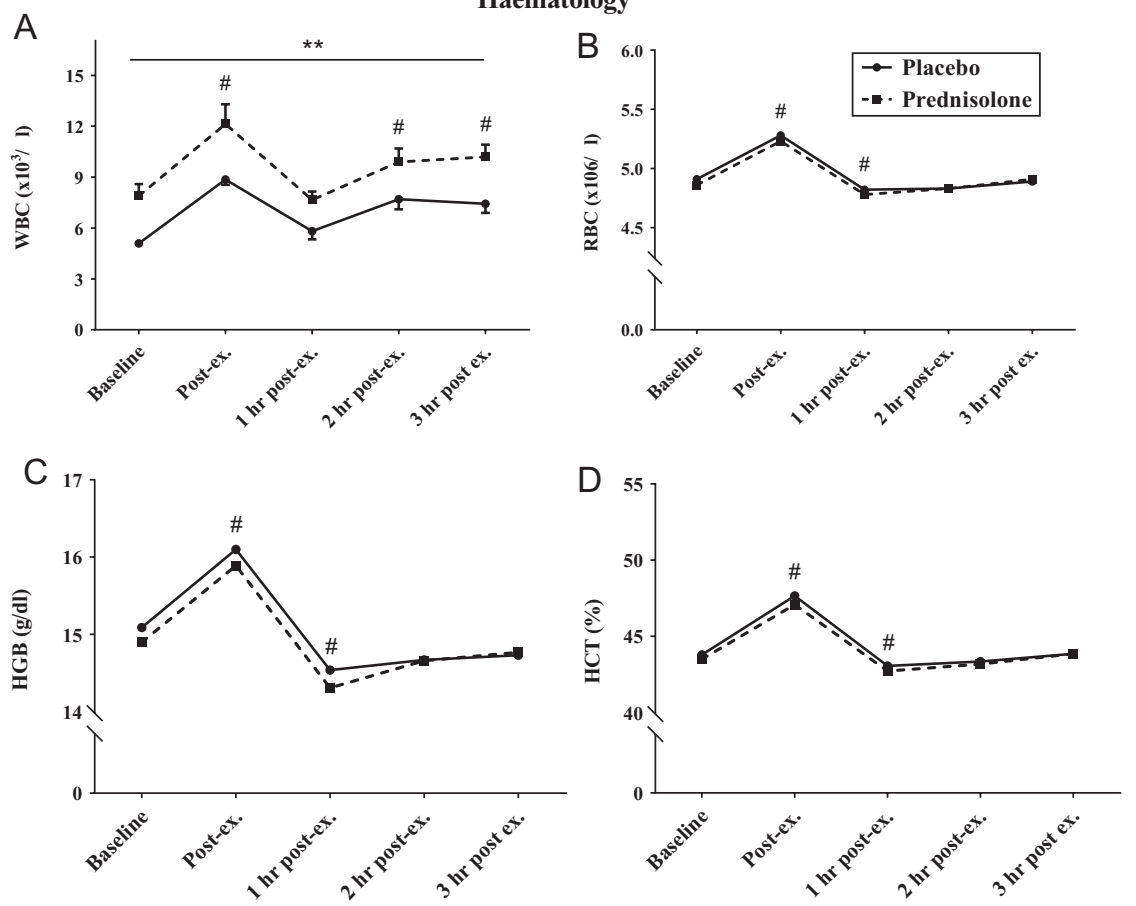

\section{Figure 3}

(A) White blood cell (WBC) count, (B) red blood cell (RBC) count, (C) haemoglobin (HGB), (D) haematocrit $(\mathrm{HCT}$ ) responses (mean \pm S.E.M.) $12 \mathrm{~h}$ post capsule ingestion (Baseline), immediately post exercise (Post-ex) and throughout recovery: $1 \mathrm{~h}, 2 \mathrm{~h}$ and $3 \mathrm{~h}$ with prednisolone and placebo treatment. ${ }^{*} P<0.01$ between prednisolone and placebo. ${ }^{*} P<0.05$ difference from baseline values with treatments combined.

reported improved exercise performance after short-term GC is equally unclear $(26,27,28)$. It could be speculated that a single dose of GC elicits a perturbation in wholebody homeostasis, including impaired glycaemic control as indicated by elevated fasting glucose and insulin. In contrast, longer duration GC treatment (albeit still short term) may promote compensatory mechanisms that are able to control this initial homeostatic insult,
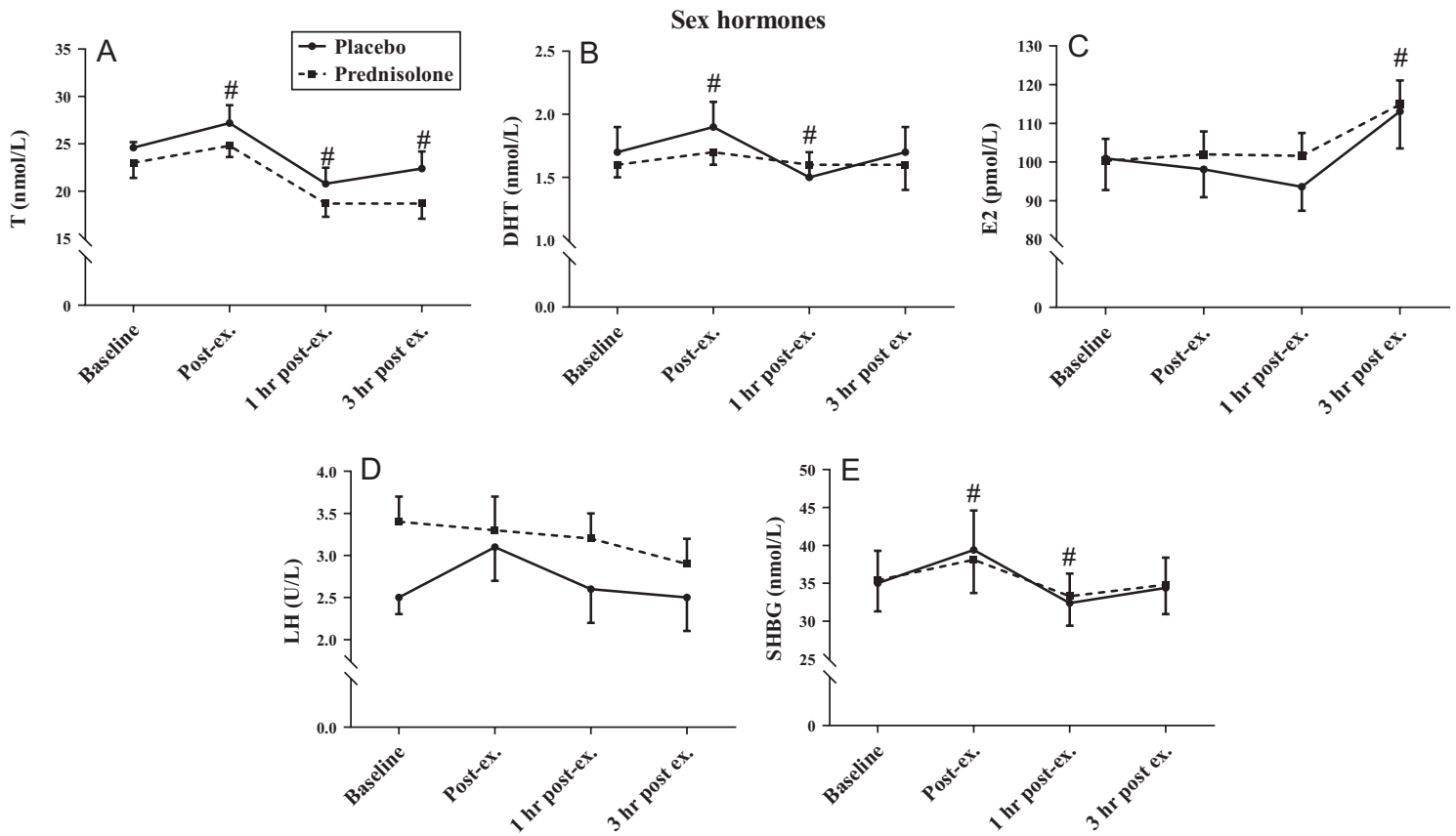

Figure 4

(A) Testosterone (T), (B) dihydrotestosterone (DHT), (C) oestradiol (E2), (D) luteinizing hormone (LH), (E) sex hormone-binding globulin (SHBG) responses (mean \pm S.E.M.) $12 \mathrm{~h}$ post capsule ingestion (Baseline), immediately post exercise (Post-ex) and throughout recovery: $1 \mathrm{~h}$ and $3 \mathrm{~h}$ with prednisolone and placebo treatment. ${ }^{\#} P<0.05$ difference from baseline values with treatments combined. 
Sex hormone ratios
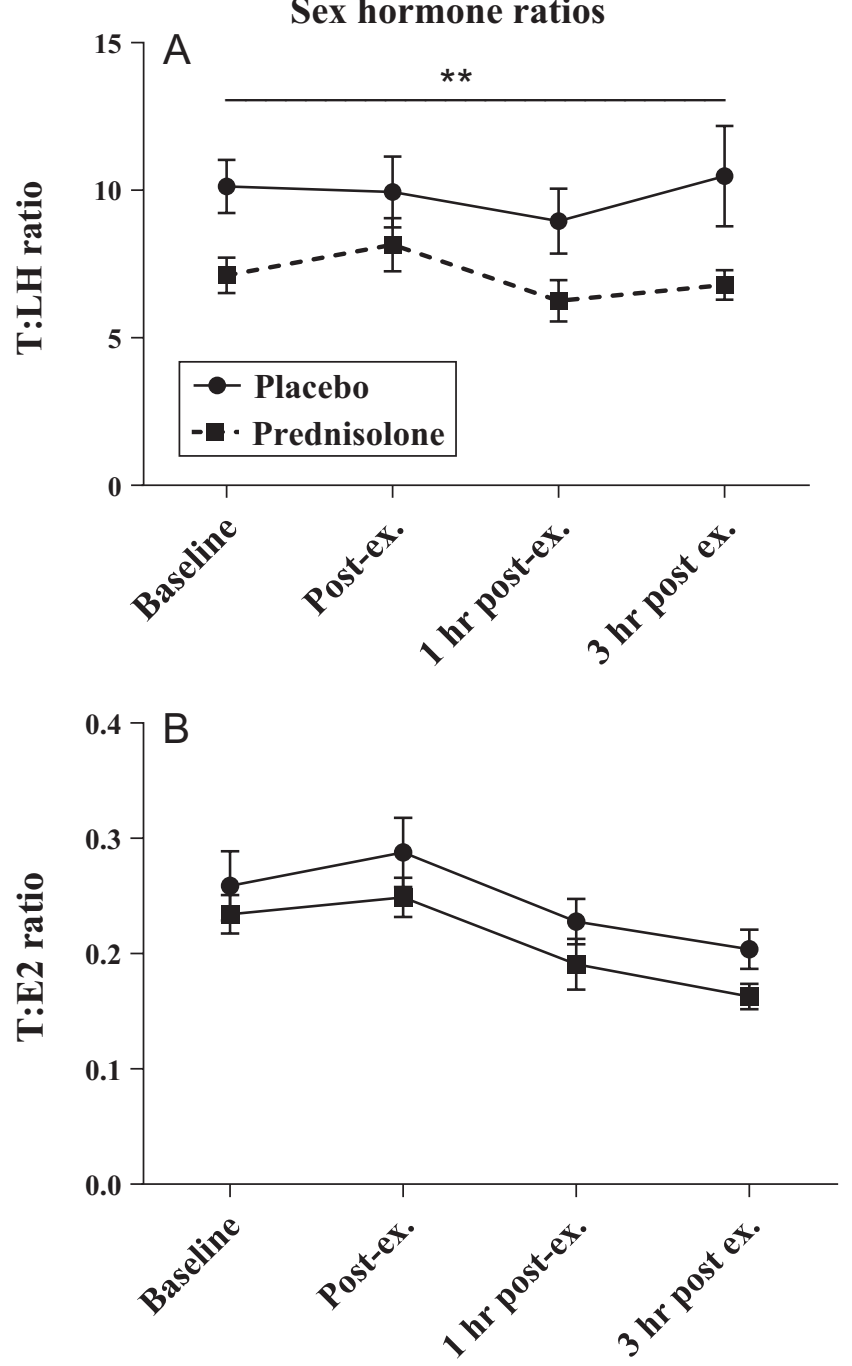

Figure 5

(A) Testosterone (T)/luteinizing hormone (LH) ratio, (B) testosterone (T)/ oestradiol (E2) ratio (mean \pm S.E.M.) $12 \mathrm{~h}$ post capsule ingestion (Baseline), immediately post exercise (Post-ex.) and throughout recovery: $1 \mathrm{~h}$ and $3 \mathrm{~h}$ with prednisolone and placebo ingestion. * $*<0.01$ between prednisolone and placebo.

which may reflect why some studies have reported normal fasting glucose and insulin after short-term GC treatment $(28,29)$. Further research is warranted to explore the effect of acute prednisolone on exercise capacity and performance during other exercises and sports and to investigate the potential mechanisms.

Chronic GC treatment is known to induce side effects including hyperglycaemia and the development of diabetes $(30,31)$. However, the effects of a single-dose GC on fasting and post-exercise blood glucose levels in healthy individuals are not clear, and some reported that prednisolone $(20 \mathrm{mg}$ ) causes an increase in blood glucose concentrations at baseline $(23,24,32)$, while others reported that it has no effect on blood glucose $(21,22,33)$. The results from the current study confirms that a single dose of prednisolone significantly increases blood glucose levels.

Exercise is known to improve insulin sensitivity and glucose regulation in healthy individuals and people who live with chronic conditions, including insulin resistance and type 2 diabetes $(34,35)$. We report that prednisoloneinduced hyperglycaemia was restored to baseline levels $3 \mathrm{~h}$ after a single session of HIIE. It is possible that the restoration of glucose levels after exercise may, in part, be due to the degradation of the biological activity of a single dose of prednisolone over the course of time. However, previous studies have also reported restoration of glucose levels when cycling exercise $\left(80-85 \%\right.$ of $\mathrm{VO}_{2 \max }$ ) is performed as little as $2-3 \mathrm{~h}$ after prednisolone (20 mg) ingestion (23). These findings highlight the important role exercise can play in improving glycaemic control during GC therapy. The effect of exercise on blood glucose may depend on the dosage of GC administered. For instance, both 1 and $4 \mathrm{mg}$ doses of dexamethasone increase blood glucose levels at baseline, however, normalisation of blood glucose with exercise at $90 \%$ of $\mathrm{VO}_{2 \max }$ occurs with only the $1 \mathrm{mg}$ dose (32). It is also possible that the normalisation of glucose levels is intensity dependant. Exercise at 70-75\% of $\mathrm{VO}_{2 \max }$ has previously been reported to have limited effect on blood glucose response following prednisolone treatment (20 mg) (24). The current findings provide new evidence that acute HIIE may help to minimise the elevation in blood glucose concentration that occurs following GC treatment. However, further research is required to confirm these findings with respect to timing of exercise following ingestion of GC and identifying the mechanisms involved (i.e. improved glucose uptake by skeletal muscle, a reduction in hepatic glucose output or both).

To determine the influence of prednisolone on other exercise-mediated metabolic responses, we measured blood lactate and changes in blood haematology. Blood lactate significantly increased from resting levels in response to HIIE with both treatments. However, the lactate response was supressed in the prednisolone trial compared to the placebo, possibly a reflection of the significant reduction in work performed during the exercise session. This finding is in contrast to previous studies which reported that blood lactate was not altered with prednisolone $(21,23,24)$ and dexamethasone treatment $(22,32)$. Furthermore, none of these studies reported a change in exercise performance, which supports the hypothesis that lactate was likely reduced in the current study due to the reduction in work completed. It is also possible that the

This work is licensed under a Creative Commons Attribution-NonCommercial-NoDerivatives 4.0 Internationab kicense.ifica com at 04/26/2023 10:53:39AM 
use of a long duration, HIIE protocol in the current study may, in part, explain the discrepancy in findings, given that lactate metabolism is crucial in sustaining intense exercise (36).

GC therapy is used as an immunosuppressive agent to treat autoimmune diseases. However, little research has been conducted to explore the immune response following GC administration and exercise. We report that acute prednisolone ingestion causes an elevation in total WBC count at baseline (12h after ingestion), and throughout the 3 -h recovery period following HIIE. Similarly, the short-term inhalation of fluticasone results in an increase in total WBC and neutrophils at baseline, with a further increase following high-intensity exercise (37). However, another study reported that lymphocyte concentration was reduced in a time-dependent manner following prednisone ingestion (38), suggesting that specific WBC subtypes may respond differently to exercise and GC ingestion, warranting further investigation.

Changes in RBC count, haemoglobin and haematocrit are reported to influence exercise performance predominantly through the contribution of oxygen to working muscles (39). Therefore, we investigated whether the decreased exercise capacity with prednisolone ingestion would coincide with changes in these variables. Although the RBC count, haemoglobin and haematocrit were altered following HIIE, there was no treatment effect of prednisolone suggesting alternative pathways are likely for the impairment of exercise capacity.

Given the potential of androgen-glucocorticoid interactions and the role of hormonal regulation for exercise performance and adaptation $(40,41)$, we explored the effects of single-dose GC treatment on circulating sex hormone concentrations before and after a single session of HIIE. We report that HIIE increased circulating androgens, namely testosterone and DHT, as well as SHBG concentrations. While DHT and SHBG returned to baseline levels during recovery, testosterone concentrations remain below baseline, suggesting a biphasic response of testosterone to HIIE. E2 concentrations were stable during exercise and increased during recovery. The ratio of testosterone/LH is reduced in men after taking prednisolone consistent with evidence of testicular, or more specifically Leydig cell, dysfunction $(42,43)$. Prednisolone reduced the ratio of testosterone/LH across all time-points consistent with an effect to impair testicular Leydig cell function superimposed on the effect of exercise. This occurred in the absence of any evidence of altered aromatase activity as the ratio of testosterone/ E2 was unchanged (44). This acute effect of prednisolone on Leydig cell function is noteworthy. Chronic GC therapy has been associated with lower circulating testosterone concentrations without elevation of $\mathrm{LH}$, attributed to suppression of central components of the HPT axis $(14,45,46)$. Our findings suggest that impairment of Leydig cell function may also play a role in the action of GC on the HPT axis. Further studies are warranted to ascertain the effects of chronic GC administration on Leydig cell function, and whether GC use impacts on multiple levels of the HPT axis.

Testosterone treatment in younger and older men has an anabolic effect including increased muscle strength and performance $(40,41)$. The acute effect of exercise to increase testosterone, DHT and SHBG could reflect an element of haemoconcentration following exercise. The reduction in testosterone post exercise but not DHT or SHBG would be consistent with downregulation of the HPT axis in the setting of fatigue. Further studies would be needed to establish whether chronic GC administration and more sustained periods of exercise might jointly impact on the function of the HPT axis to the detriment of exercise capacity.

This study has several potential limitations; first, there is a relatively small sample size. This study was conducted as part of a larger, invasive study, and as such, recruitment was difficult (18). This study was adequately powered to compare changes in blood glucose from baseline to $3 \mathrm{~h}$ post exercise, between placebo and prednisolone, $P<0.05$, effect size of $2.65 ; n=9$; power of $99 \%$, which was the main outcome of the project. We also identified a significant difference in watts between placebo and prednisolone; however, a post hoc power calculation ( $\mathrm{G}^{*}$ Power 3.1.9.2; two-tailed dependent $t$-test, alpha $=0.05)$ demonstrated that it was underpowered (effect size of $0.41 ; n=9$; power of $23 \%$ ). As such, future studies should include a larger sample size to account for an adequate power. Second, due to the metabolic differences between males and females, only males were tested in this study. As such, and acknowledging the differences in reproductive physiology between males and females, the results may not be applicable to females. It will be important to conduct further research in females to identify whether GC treatment has a different effect. Furthermore, the participants in this study were young and healthy, and as such these findings are delimited to this specific population with further research require to explore the effects of GC ingestion and exercise in other populations. Finally, the participants were given access to water ad libitum, it is possible that some of the changes in the haematological outcomes may be due to alterations in plasma volume.

This work is licensed under a Creative Commons Attribution-NonCommercial-NoDerivatives 4.0 Internationab kicense.ifica com at $04 / 26 / 2023$ 10:53:39AM 
In conclusion, a single dose of prednisolone decreases work performed during high-intensity interval cycling that suggests that acute GC administration does not act as an ergogenic aid, and in fact may reduce exercise performance. Prednisolone also increases basal blood glucose concentrations, impairs Leydig cell function and increases WBC count. Importantly, acute HIIE restores euglycaemia which may indicate HIIE as a potential treatment strategy for counteracting GC-induced hyperglycaemia. Whether HIIE training can reduce the serious metabolic side effects of chronic GC administration warrants further investigation.

\section{Declaration of interest}

The authors declare that there is no conflict of interest that could be perceived as prejudicing the impartiality of the research reported.

\section{Funding}

This research did not receive any specific grant from any funding agency in the public, commercial or not-for-profit sector.

\section{Acknowledgements}

Itamar Levinger was supported by the Heart Foundation (ID: 100040). The authors wish to thank the men who participated in this study for their time and effort.

\section{References}

1 Fragala MS, Kraemer WJ, Denegar CR, Maresh CM, Mastro AM \& Volek JS. Neuroendocrine-and responses to exercise. Sports Medicine 201141 621-639. (https://doi.org/10.2165/11590430-00000000000000)

2 Webster JI, Tonelli L \& Sternberg EM. Neuroendocrine regulation of immunity. Annual Review of Immunology 200220 125-163. (https:// doi.org/10.1146/annurev.immunol.20.082401.104914)

3 Fardet L, Petersen I \& Nazareth I. [Description of oral glucocorticoid prescriptions in general population]. La Revue de Medecine Interne 201132 594-599. (https://doi.org/10.1016/j.revmed.2011.02.022)

4 Overman RA, Yeh JY \& Deal CL. Prevalence of oral glucocorticoid usage in the United States: a general population perspective. Arthritis Care and Research 201365 294-298. (https://doi.org/10.1002/ acr.21796)

5 Laugesen K, Jorgensen JOL, Sorensen HT \& Petersen I. Systemic glucocorticoid use in Denmark: a population-based prevalence study. BMJ Open 20177 e015237. (https://doi.org/10.1136/ bmjopen-2016-015237)

6 Benard-Laribiere A, Pariente A, Pambrun E, Begaud B, Fardet L \& Noize P. Prevalence and prescription patterns of oral glucocorticoids in adults: a retrospective cross-sectional and cohort analysis in France. BMJ Open 20177 e015905. (https://doi.org/10.1136/ bmjopen-2017-015905)

7 Tacey A, Parker L, Garnham A, Brennan-Speranza TC \& Levinger I. The effect of acute and short term glucocorticoid administration on exercise capacity and metabolism. Journal of Science and Medicine in Sport 201720 543-548. (https://doi.org/10.1016/j.jsams.2016.10.016)

8 Collomp K, Arlettaz A, Buisson C, Lecoq AM \& Mongongu C. Glucocorticoid administration in athletes: performance, metabolism and detection. Steroids 2016115 193-202. (https://doi.org/10.1016/j. steroids.2016.09.008)

9 Harris E, Tiganescu A, Tubeuf S \& Mackie SL. The prediction and monitoring of toxicity associated with long-term systemic glucocorticoid therapy. Current Rheumatology Reports 201517513. (https://doi.org/10.1007/s11926-015-0513-4)

10 Liu D, Ahmet A, Ward L, Krishnamoorthy P, Mandelcorn ED, Leigh R, Brown JP, Cohen A \& Kim H. A practical guide to the monitoring and management of the complications of systemic corticosteroid therapy. Allergy, Asthma, and Clinical Immunology 2013 9 30. (https://doi.org/10.1186/1710-1492-9-30)

11 Pinheiro CHdJ, Sousa Filho WMd, Oliveira Neto Jd, Marinho Mde J, Motta Neto R, Smith MMRL \& Silva CABd. Exercise prevents cardiometabolic alterations induced by chronic use of glucocorticoids. Arquivos Brasileiros De Cardiologia 200993 400-408, 392. (https://doi.org/10.1590/S0066-782X2009001000014)

12 Dionisio TJ, Louzada JC, Viscelli BA, Dionisio EJ, Martuscelli AM, Barel M, Perez OA, Bosqueiro JR, Brozoski DT, Santos CF, et al. Aerobic training prevents dexamethasone-induced peripheral insulin resistance. Hormone and Metabolic Research 201446 484-489. (https:// doi.org/10.1055/s-0034-1370990)

13 LaPier TK. Glucocorticoid-induced muscle atrophy: the role of exercise in treatment and prevention. Journal of Cardiopulmonary Rehabilitation 199717 76-84. (https://doi.org/10.1097/00008483199703000-00002)

14 Morrison D, Capewell S, Reynolds SP, Thomas J, Ali NJ, Read GF, Henley R \& Riad-Fahmy D. Testosterone levels during systemic and inhaled corticosteroid therapy. Respiratory Medicine 1994 88 659-663. (https://doi.org/10.1016/S0954-6111(05)80062-9)

15 Kuusmaa M, Schumann M, Sedliak M, Kraemer WJ, Newton RU, Malinen JP, Nyman K, Hakkinen A \& Hakkinen K. Effects of morning versus evening combined strength and endurance training on physical performance, muscle hypertrophy, and serum hormone concentrations. Applied Physiology, Nutrition, and Metabolism 201641 1285-1294. (https://doi.org/10.1139/apnm-2016-0271)

16 Ahtiainen JP, Nyman K, Huhtaniemi I, Parviainen T, Helste M, Rannikko A, Kraemer WJ \& Hakkinen K. Effects of resistance training on testosterone metabolism in younger and older men. Experimental Gerontology 201569 148-158. (https://doi.org/10.1016/j. exger.2015.06.010)

17 Levinger I, Brennan-Speranza TC, Stepto NK, Jerums G, Parker L, McConell GK, Anderson M, Garnham A, Hare DL, Ebeling PR, et al. A single dose of prednisolone as a modulator of undercarboxylated osteocalcin and insulin sensitivity post-exercise in healthy young men: A study protocol. JMIR Research Protocols 20165 e78. (https:// doi.org/10.2196/resprot.5119)

18 Parker L, Lin X, Garnham A, McConell G, Stepto NK, Hare DL, Byrnes E, Ebeling PR, Seeman E, Brennan-Speranza TC, et al. Glucocorticoid-induced insulin resistance in men is associated With suppressed undercarboxylated osteocalcin. Journal of Bone and Mineral Research 201934 49-58. (https://doi.org/10.1002/jbmr.3574)

19 Parker L, Stepto NK, Shaw CS, Serpiello FR, Anderson M, Hare DL \& Levinger I. Acute high-intensity interval exercise-induced redox signaling is associated with enhanced insulin sensitivity in obese middle-aged men. Frontiers in Physiology 20167 411. (https://doi. org/10.3389/fphys.2016.00411)

20 Gibala MJ, Little JP, Macdonald MJ \& Hawley JA. Physiological adaptations to low-volume, high-intensity interval training in health and disease. Journal of Physiology 2012590 1077-1084. (https://doi. org/10.1113/jphysiol.2011.224725)

21 Arlettaz A, Portier H, Lecoq AM, Labsy Z, de Ceaurriz J \& Collomp K. Effects of acute prednisolone intake on substrate utilization during submaximal exercise. International Journal of Sports Medicine 200829 21-26. (https://doi.org/10.1055/s-2007-964994)

22 Petrides JS, Mueller GP, Kalogeras KT, Chrousos GP, Gold PW \& Deuster PA. Exercise-induced activation of the hypothalamic- https://ec.bioscientifica.com https://doi.org/10.1530/EC-18-0473 (c) 2019 The authors Published by Bioscientifica Ltd
This work is licensed under a Creative Commons Attribution-NonCommercial-NoDerivatives 4.0 Internationab ticense.ifica com at $04 / 26 / 2023$ 10:53:39AM 
pituitary-adrenal axis: marked differences in the sensitivity to glucocorticoid suppression. Journal of Clinical Endocrinology and Metabolism 199479 377-383. (https://doi.org/10.1210/ jcem.79.2.8045951)

23 Arlettaz A, Collomp K, Portier H, Lecoq AM, Pelle A \& de Ceaurriz J. Effects of acute prednisolone intake during intense submaximal exercise. International Journal of Sports Medicine 200627 673-679. (https://doi.org/10.1055/s-2005-872826)

24 Arlettaz A, Collomp K, Portier H, Lecoq AM, Rieth N, Le Panse B $\&$ De Ceaurriz J. Effects of acute prednisolone administration on exercise endurance and metabolism. British Journal of Sports Medicine 200842 250-254; discussion 254. (https://doi.org/10.1136/ bjsm.2007.039040)

25 van Raalte DH, Diamant M, Ouwens DM, Ijzerman RG, Linssen MM Guigas B, Eringa EC \& Serne EH. Glucocorticoid treatment impairs microvascular function in healthy men in association with its adverse effects on glucose metabolism and blood pressure: a randomised controlled trial. Diabetologia 201356 2383-2391. (https://doi.org/10.1007/s00125-013-3016-8)

26 Arlettaz A, Portier H, Lecoq AM, Rieth N, De Ceaurriz J \& Collomp K. Effects of short-term prednisolone intake during submaximal exercise. Medicine and Science in Sports and Exercise 200739 1672-1678. (https://doi.org/10.1249/mss.0b013e3180dc992c)

27 Collomp K, Arlettaz A, Portier H, Lecoq AM, Le Panse B, Rieth N $\&$ De Ceaurriz J. Short-term glucocorticoid intake combined with intense training on performance and hormonal responses. British Journal of Sports Medicine 200842 983-988. (https://doi.org/10.1136/ bjsm.2007.043083)

28 Le Panse B, Thomasson R, Jollin L, Lecoq AM, Amiot V, Rieth N, De Ceaurriz J \& Collomp K. Short-term glucocorticoid intake improves exercise endurance in healthy recreationally trained women. European Journal of Applied Physiology 2009107 437-443. (https://doi. org/10.1007/s00421-009-1149-8)

29 Nordsborg N, Ovesen J, Thomassen M, Zangenberg M, Jons C, Iaia FM, Nielsen JJ \& Bangsbo J. Effect of dexamethasone on skeletal muscle $\mathrm{Na}+\mathrm{K}+$ pump subunit specific expression and $\mathrm{K}+$ homeostasis during exercise in humans. Journal of Physiology $2008 \mathbf{5 8 6}$ 1447-1459. (https://doi.org/10.1113/jphysiol.2007.143073)

30 Yuen KC, McDaniel PA \& Riddle MC. Twenty-four-hour profiles of plasma glucose, insulin, C-peptide and free fatty acid in subjects with varying degrees of glucose tolerance following short-term, mediumdose prednisone (20 mg/day) treatment: evidence for differing effects on insulin secretion and action. Clinical Endocrinology $2012 \mathbf{7 7}$ 224-232. (https://doi.org/10.1111/j.1365-2265.2011.04242.x)

31 Burt MG, Roberts GW, Aguilar-Loza NR, Frith P \& Stranks SN. Continuous monitoring of circadian glycemic patterns in patients receiving prednisolone for COPD. Journal of Clinical Endocrinology and Metabolism 201196 1789-1796. (https://doi.org/10.1210/jc.20102729)

32 Deuster PA, Petrides JS, Singh A, Chrousos GP \& Poth M. Endocrine response to high-intensity exercise: dose-dependent effects of dexamethasone. Journal of Clinical Endocrinology and Metabolism 2000 85 1066-1073. (https://doi.org/10.1210/jcem.85.3.6444)

33 Deuster PA, Petrides JS, Singh A, Lucci EB, Chrousos GP \& Gold PW. High intensity exercise promotes escape of adrenocorticotropin and cortisol from suppression by dexamethasone: sexually dimorphic responses. Journal of Clinical Endocrinology and Metabolism $1998 \mathbf{8 3}$ 3332-3338. (https://doi.org/10.1210/jcem.83.9.5110)
34 Colberg SR, Sigal RJ, Fernhall B, Regensteiner JG, Blissmer BJ, Rubin RR, Chasan-Taber L, Albright AL \& Braun B. Exercise and type 2 diabetes: the American College of Sports Medicine and the American Diabetes Association: joint position statement. Diabetes Care 201033 e147-e167. (https://doi.org/10.2337/dc10-9990)

35 Parker L, Stepto NK, Shaw CS, Serpiello FR, Anderson M, Hare DL \& Levinger I. Acute high-intensity interval exercise-induced redox signaling is associated with enhanced insulin sensitivity in obese middle-aged men. Frontiers in Physiology 20167 411. (https://doi. org/10.3389/fphys.2016.00411)

36 Baker JS, McCormick MC \& Robergs RA. Interaction among skeletal muscle metabolic energy systems during intense exercise. Journal of Nutrition and Metabolism 20102010 905612. (https://doi. org/10.1155/2010/905612)

37 Schwindt CD, Zaldivar F, Eliakim A, Shin HW, Leu SY \& Cooper DM Inhaled fluticasone and the hormonal and inflammatory response to brief exercise. Medicine and Science in Sports and Exercise 201042 1802-1808. (https://doi.org/10.1249/MSS.0b013e3181dd089d)

38 Yu DT, Clements PJ \& Pearson CM. Effect of corticosteroids on exercise-induced lymphocytosis. Clinical and Experimental Immunology 197728 326-331.

39 Mairbaurl H. Red blood cells in sports: effects of exercise and training on oxygen supply by red blood cells. Frontiers in Physiology 20134 332. (https://doi.org/10.3389/fphys.2013.00332)

40 Bhasin S, Woodhouse L, Casaburi R, Singh AB, Mac RP, Lee M, Yarasheski KE, Sinha-Hikim I, Dzekov C, Dzekov J, et al. Older men are as responsive as young men to the anabolic effects of graded doses of testosterone on the skeletal muscle. Journal of Clinical Endocrinology and Metabolism 200590 678-688. (https://doi. org/10.1210/jc.2004-1184)

41 Page ST, Amory JK, Bowman FD, Anawalt BD, Matsumoto AM, Bremner WJ \& Tenover JL. Exogenous testosterone (T) alone or with finasteride increases physical performance, grip strength, and lean body mass in older men with low serum T. Journal of Clinical Endocrinology and Metabolism 200590 1502-1510. (https://doi. org/10.1210/jc.2004-1933)

42 Andersson AM, Jorgensen N, Frydelund-Larsen L, Rajpert-De Meyts E \& Skakkebaek NE. Impaired Leydig cell function in infertile men: a study of 357 idiopathic infertile men and 318 proven fertile controls. Journal of Clinical Endocrinology and Metabolism 200489 3161-3167. (https://doi.org/10.1210/jc.2003-031786)

43 Lardone MC, Piottante A, Valdevenito R, Ebensperger M \& Castro A. Histological and hormonal testicular function in oligo/azoospermic infertile men. Andrologia 201345 379-385. (https://doi.org/10.1111/ and.12026)

44 Lardone MC, Argandona F, Florez M, Parada-Bustamante A, Ebensperger M, Palma C, Piottante A \& Castro A. Overexpression of CYP19A1 aromatase in Leydig cells is associated with steroidogenic dysfunction in subjects with Sertoli cell-only syndrome. Andrology 20175 41-48. (https://doi.org/10.1111/andr.12289)

45 Contreras LN, Masini AM, Danna MM, Kral M, Bruno OD, Rossi MA \& Andrada JA. Glucocorticoids: their role on gonadal function and LH secretion. Minerva Endocrinologica 199621 43-46.

46 Kamischke A, Kemper DE, Castel MA, Luthke M, Rolf C, Behre HM, Magnussen $\mathrm{H}$ \& Nieschlag E. Testosterone levels in men with chronic obstructive pulmonary disease with or without glucocorticoid therapy. European Respiratory Journal 199811 41-45. (https://doi.org/ 10.1183/09031936.98.11010041)

Received in final form 17 January 2019

Accepted 23 January 2019

Accepted Preprint published online 23 January 2019 https://ec.bioscientifica.com https://doi.org/10.1530/EC-18-0473 (c) 2019 The authors Published by Bioscientifica Ltd

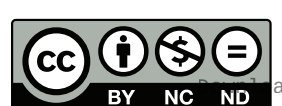

This work is licensed under a Creative Commons Attribution-NonCommercial-NoDerivatives 4.0 Internationab ticense.ifica com at $04 / 26 / 2023$ 10:53:39AM 